\title{
Long-term results after nailing in situ of slipped upper femoral epiphysis
}

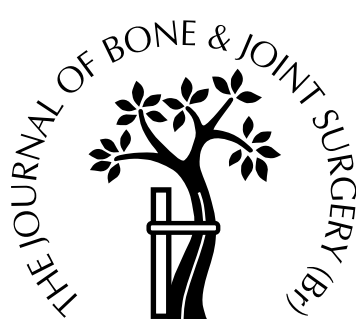

\author{
A 30-YEAR FOLLOW-UP OF 59 HIPS \\ G. Hansson, L. Billing, B. Högstedt, R. Jerre, J. Wallin \\ From the Central Hospital, Halmstad and the Östra Hospital, Gothenburg, Sweden
}

$\mathbf{W}$ e reviewed the radiological and clinical long-term results after the nailing in situ of slipped upper femoral epiphysis in 59 hips in 43 patients. The displacement of the epiphysis had been measured as the 'slipping angle' before operation and related to the results at follow-up at a mean of 30.9 years (27 to 34). The mean age at follow-up was 44.2 years (39 to 50).

Radiographic re-examination of 41 hips with slipping angles of $\leq 30^{\circ}$ at the time of operation showed that eight $(\mathbf{2 0 \%})$ had developed mild osteoarthritis and one had severe changes. For 18 hips with slipping angles ranging from 31 to $50^{\circ}$ at surgery six $(33 \%)$ had mild osteoarthritis and three had severe changes. The differences did not quite achieve statistical significance $(p=0.09)$.

Clinical re-examination of the 41 hips with slipping angles of $\leq 30^{\circ}$ showed fair or poor results (Harris hip score $<90)$ in three $(7 \%)$. In the 18 hips with slipping of 31 to $50^{\circ}$, four had fair or poor results $(22 \%)$ $(p=0.13)$.

We conclude that nailing in situ for slipping of $\leq 30^{\circ}$, using one thin nail, can give excellent long-term results. At present we recommend that hips with slips ranging from 31 to $50^{\circ}$ should also be nailed in situ, but further long-term studies are required, especially on the choice between nailing in situ and corrective osteotomy for slips in excess of $50^{\circ}$.

J Bone Joint Surg [Br] 1998;80-B:70-7.

Received 19 September 1996; Accepted after revision 17 July 1997

G. Hansson, MD, PhD, Associate Professor

Department of Orthopaedics

B. Högstedt, MD, PhD

Department of Occupational Medicine

Central Hospital, S-301 85 Halmstad, Sweden.

R. Jerre, MD

Department of Orthopaedics

L. Billing, MD, PhD, Radiologist

J. Wallin, MD

Department of Diagnostic Radiology

Östra Hospital, S-416 85 Gothenburg, Sweden.

Correspondence should be sent to Dr G. Hansson.

(C)1998 British Editorial Society of Bone and Joint Surgery 0301-620X/98/17268 \$2.00
The treatment of slipped upper femoral epiphysis (SUFE) aims to prevent further slipping and minimise the risk of later osteoarthritis (OA) of the hip. ${ }^{1-3}$ Closed reduction has been associated with a high risk of avascular necrosis, 4,5 and therefore mild slipping is usually treated without trying to restore the anatomical position, either by nailing in situ $^{6-8}$ or by bone-peg epiphysiodesis. ${ }^{9-11}$ In some hips with moderate or severe displacement, realignment of the epiphysis has been advised either directly by subcapital osteotomy or indirectly by intertrochanteric or subtrochanteric osteotomy. $^{12-15}$ These osteotomies are difficult to perform and the subcapital operation, which offers the best anatomical restoration, is associated with a high incidence of avascular necrosis. ${ }^{16-18}$ To our knowledge, there is not enough data to allow a reliable decision as to when displacement is severe enough to justify any of these operations.

In the 1950s, the late Professor Erik Severin, with one of the present authors (LB), started a prospective study of patients with SUFE. The main aim was to investigate the results after nailing in situ in relation to the degree of displacement of the epiphysis at the time of surgery. The primary results were reported in $1959 .{ }^{19}$ These patients have now reached middle age, and we therefore decided to re-examine them to review the long-term results. In all, 59 affected hips in 43 patients were seen again: the incidence of $\mathrm{OA}$ and the clinical results were studied in relation to 'slipping angle' (SA) at surgery and to other risk factors.

\section{Patients and Methods}

Between 1946 and 1959, 120 patients had been admitted with SUFE to the Department of Orthopaedics, Sahlgrenska Hospital, Gothenburg, Sweden. From these we selected patients on the following criteria:

1) Availability of either the primary radiographs or reliable data from measurements at the time of operation.

2) Treatment by nailing in situ using a single thin Nyström nail.

3) No further slipping after the primary nailing.

We selected 47 patients of whom 43, 26 men and 17 women, with 59 affected hips had clinical and radiological re-examination. In all 59 hips slipping was assessed as 


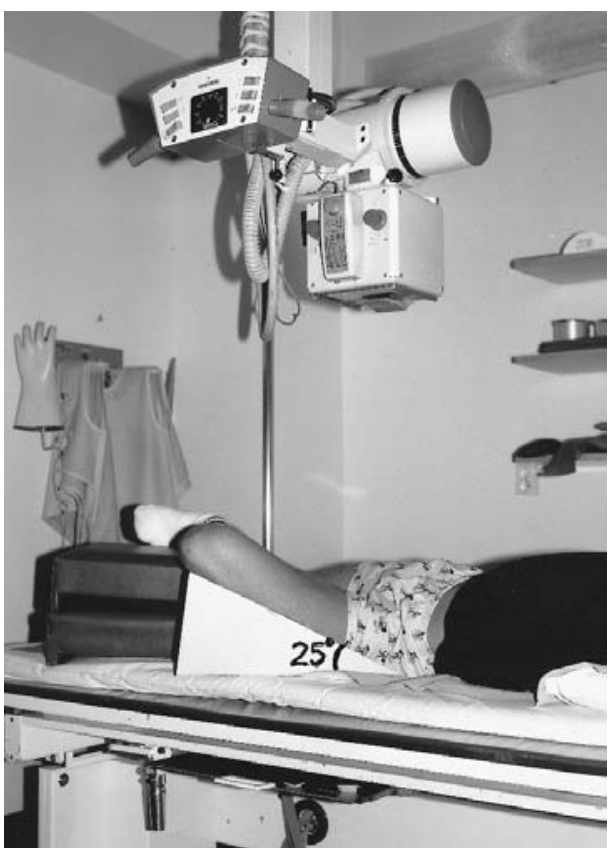

Fig. 1a

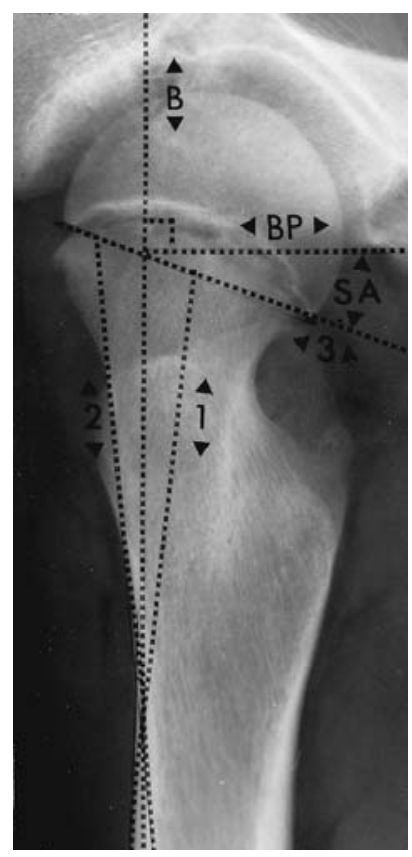

Fig. 1b

Measurement of the displacement of the upper femoral epiphysis on a lateral view by a modification of Billing's technique. Displacement is in a posterior direction, and reliable measurement therefore requires a standard and exactly defined position for the lateral view. Figure $1 \mathrm{a}$ - With the patient supine and the knee flexed to $90^{\circ}$, the femur is externally rotated $90^{\circ}$ by placing the lower leg horizontally on a box. The femur is elevated by $25^{\circ}$ from the table. Each hip is examined separately; the pelvis may be rotated 60 to $70^{\circ}$ if necessary in patients with restricted range of hip movement. Figure $1 \mathrm{~b}-$ The slipping angle (SA which is 90-epiphyseal plane angle) is defined as the angle between the line (3) connecting the corners of the femoral epiphysis and a line (BP) which is perpendicular to one (B) which bisects a line parallel to the anterior cortex of the upper femoral diaphysis (1) and a line parallel to the anterior cortex of the lower femoral neck (2).

chronic either from radiographs obtained before surgery or because hip symptoms had been present for three weeks or more. The mean age at surgery was 13.4 years (9 to 17 ), the mean duration of follow-up was 30.9 years (27 to 34) and the mean age at review 44.2 years (39 to 50).

Radiological measurements. Standard lateral radiographs of both proximal femora had been obtained separately at the time of surgery using the Billing technique. ${ }^{20}$ Radiographs were available for 54 hips (92\%), and the SA was remeasured by one of the authors (JW) (Fig. 1). An SA of $6^{\circ}$ or less was recorded as normal, 7 to $12^{\circ}$ as uncertain and $13^{\circ}$ or more as definite displacement. ${ }^{21}$ For uncertain cases additional radiological signs of minor slipping were looked for, such as remodelling at the junction between the epiphysis and the femoral neck by absorption or bone deposition. If such additional radiological signs were present in hips with an SA of between 7 and $12^{\circ}$ they were recorded as definite slips. For the five hips without original radiographs, data on the epiphyseal plane angle (EPPA) of Billing ${ }^{20}$ were available and were used to calculate the SA (SA $=90-$ EPPA).

To assess inter- and intraobserver agreement on the measurement of the SA, two of the authors (RJ and JW) independently measured the SA twice within intervals of at least one week in 50 randomly selected radiographs. We calculated the mean intra- and interobserver differences.

Operative techniques. For hips with severely displaced epiphyses, the Nyström nail was inserted ventrally in the anterior part of the femur to place it in the centre of the epiphysis (Fig. 2). ${ }^{7,19}$ Full weight-bearing was allowed as soon as the wound had healed, and radiographs of both hips were obtained at three- to four-monthly intervals until the growth plate had fused. If the tip of the nail was shown not to have stayed in the epiphysis, either because the nail had slipped or because the femoral neck had continued to grow, renailing was undertaken. When growth was complete the nail was removed.

Review radiographics. Five views were obtained of each hip $^{22}$ at the long-term review: 1) non-weight-bearing AP; 2) non-weight-bearing lateral (Billing method ${ }^{20}$ ); 3) weightbearing AP; 4) weight-bearing anterolateral oblique; and 5) weight-bearing posterolateral oblique.

These views showed the whole circumference of the joint space. We classified narrowing as mild when the superior joint space measured $>2.0 \leq 3.0 \mathrm{~mm}$ and/or the anterior and/or posterior joint space measured 


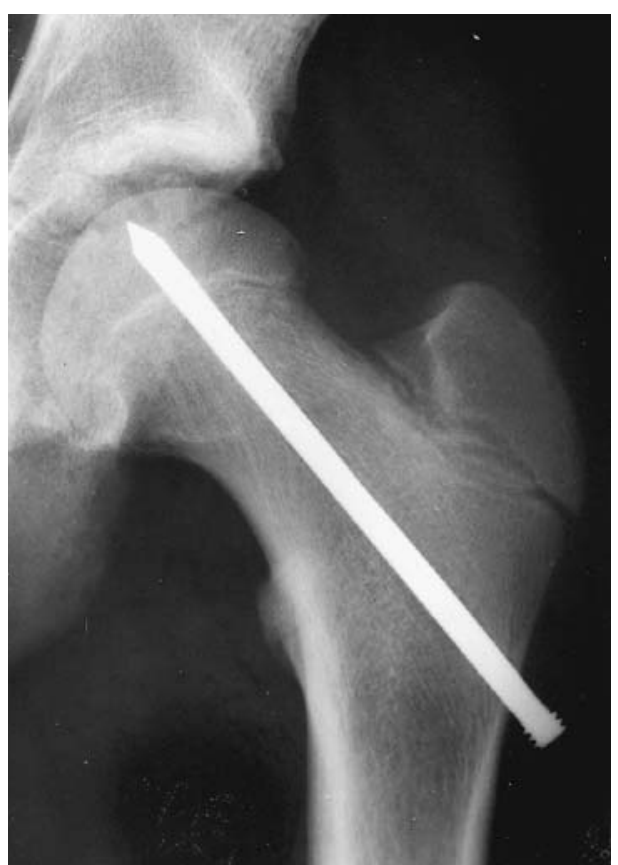

Fig. 2a

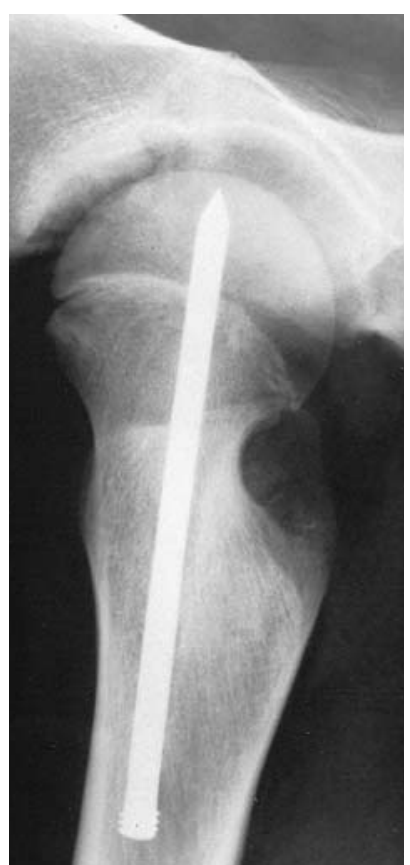

Fig. 2b

Radiographs of a hip with an SA of $22^{\circ}$ nailed in situ using a single Nyström nail. On both views the nail enters the central part of the epiphysis.

$>1.5 \leq 2.5 \mathrm{~mm}$, and severe when the superior joint space measured $\leq 2.0 \mathrm{~mm}$ and/or the anterior and/or posterior joint space measured $\leq 1.5 \mathrm{~mm}$. $^{22}$ To assess inter- and intraobserver agreement two authors (RJ and JW) measured the radiographs of 50 reviewed hips on all five views independently at an interval of at least one week.

The radiographs were analysed in relation to the SA at surgery and also according to the following risk factors: gender, unilateral or bilateral, history of trauma, need for repinning, duration of hip symptoms before surgery, age at surgery and age at follow-up.

Clinical review. We used the Harris hip score (HHS) to assess the functional results. ${ }^{23}$ Each hip score of $\geq 90$ points was classified as excellent and $<90$ points as fair or poor. The results were then again analysed in relation to SA at surgery and to risk factors.

Statistics. In the statistical analysis, we used the chisquared test to calculate differences between groups and the Mann-Whitney U test (two-tailed test) to compare mean values. We used Student's $t$-test for paired comparisons to assess inter- and intraobserver agreement on the measurement of radiographs. $\mathrm{P}$ values of less than 0.05 were considered significant.

\section{Results}

In the 59 hips having late review the radiographs showed a reduction of joint space in 18 (31\%); 14 showed mild changes and four had severe change (7\%) (Table I; Fig. 3).
In two of these four hips the diminished joint space could only be seen on the modified frog lateral view. Comparison between the mean SA at surgery in hips with narrowing and that in hips with no such changes gave a $p$ value of 0.09 (Table I; Fig. 4). None of the risk factors showed a statistically significant relationship to an increased risk of developing osteoarthritis ( $\mathrm{p}=0.09$ to 0.64 ).

The HHS was fair or poor in seven hips (12\%) (Table II; Fig.5). Again, we found a trend in relation to SA at surgery, but no statistically significant difference $(p=0.13$; Fig. 5). Of the eight risk factors only two could identify hips with poor prognosis i.e., poor clinical results were seen significantly more often in patients with unilateral than in those with bilateral slips ( $p=0.02$; Table II) and in women than in men $(p=0.047)$. In three of the seven hips with a hip score of $<90$, the joint spaces were normal in all five views in the review radiographs.

Correlation between radiological and clinical results. For the 41 hips with normal joint spaces the HHS was 95.9 \pm 7.7 (54 to 100 ), for the 14 hips with mild OA, $96.5 \pm 6.2$ (75 to 100) and for the four with severe OA, $74.3 \pm 28.3$ (34 to 100) (Table III).

Complications. There were complications related to the operation in 15 hips (25\%). Ten hips needed renailing because the femoral neck had grown so much that the nail lost its anchorage in the epiphysis. In these, the SA at the primary nailing was significantly smaller $\left(20.0 \pm 6.3^{\circ}\right)$ than in the remaining 49 hips $\left(27.6 \pm 10.8^{\circ}, \mathrm{p}=0.003\right)$. The age at primary nailing was also significantly lower in the 
Table I. Clinical details related to the occurrence of osteoarthritis of 59 hips treated for SUFE 30 years after nailing in situ

\begin{tabular}{|c|c|c|c|}
\hline & \multicolumn{2}{|l|}{ Osteoarthritis } & \multirow[b]{2}{*}{ p value } \\
\hline & Yes & No & \\
\hline $\begin{array}{l}\text { Gender } \\
\text { Female } \\
\text { Male }\end{array}$ & $\begin{array}{l}9 \\
9\end{array}$ & $\begin{array}{l}13 \\
28\end{array}$ & $0.18^{*}$ \\
\hline $\begin{array}{l}\text { Unilateral/bilateral slipping } \\
\text { Unilateral } \\
\text { Bilateral }\end{array}$ & $\begin{array}{r}5 \\
13\end{array}$ & $\begin{array}{r}8 \\
33\end{array}$ & $0.48 *$ \\
\hline $\begin{array}{l}\text { History of trauma } \\
\text { Yes } \\
\text { No }\end{array}$ & $\begin{array}{r}3 \\
15\end{array}$ & $\begin{array}{r}9 \\
32\end{array}$ & $0.64 *$ \\
\hline $\begin{array}{l}\text { Repinning } \\
\text { Yes } \\
\text { No }\end{array}$ & $\begin{array}{r}3 \\
15\end{array}$ & $\begin{array}{l}10 \\
31\end{array}$ & $0.51 *$ \\
\hline $\begin{array}{l}\text { Mean ( } \pm \text { SD; range) } \\
\text { duration of hip symptoms } \\
\text { before surgery (mth) } \dagger\end{array}$ & $7.2 \pm 5.3(1$ to 18$)$ & $4.5 \pm 2.8(1$ to 12$)$ & $0.13 \neq$ \\
\hline $\begin{array}{l}\text { Mean ( } \pm \text { SD; range) } \\
\text { SA at surgery (degrees) }\end{array}$ & $30.2 \pm 11.4(9$ to 45$)$ & $24.6 \pm 9.8(12$ to 50$)$ & $0.09 \neq$ \\
\hline $\begin{array}{l}\text { Mean age ( } \pm \mathrm{SD} \text {; range }) \\
\text { at surgery }(\mathrm{yr})\end{array}$ & $13.8 \pm 2.0(10$ to 17$)$ & $13.2 \pm 1.7(9$ to 16$)$ & $0.29 \neq$ \\
\hline $\begin{array}{l}\text { Mean ( } \pm \mathrm{SD} ; \text { range) } \\
\text { age at follow-up (yr) }\end{array}$ & $44.9 \pm 3.0(40$ to 50$)$ & $44.0 \pm 2.1(39$ to 48$)$ & $0.21 \neq$ \\
\hline
\end{tabular}
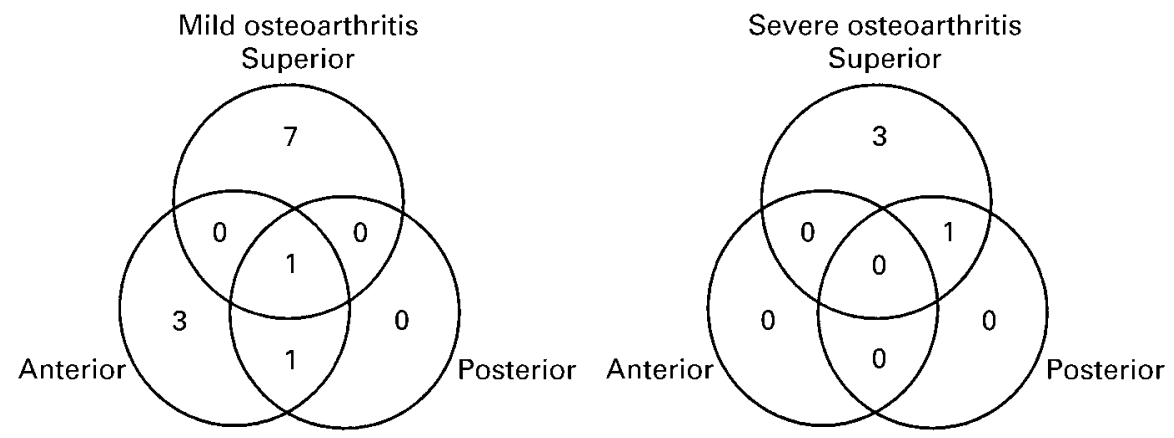

Fig. 3

Venn diagram showing the location of the joint-space narrowing in 16 standing radiographs. In another two hips narrowing was seen only on modified frog lateral views with the patients supine.

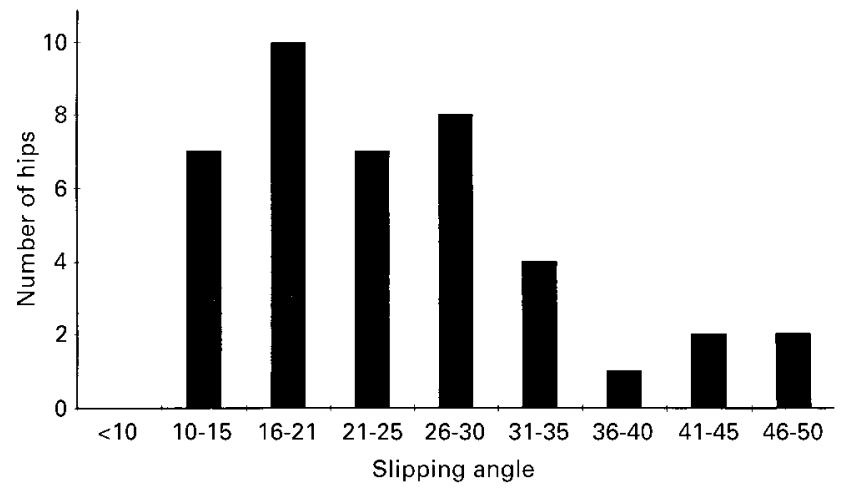

Fig. 4a

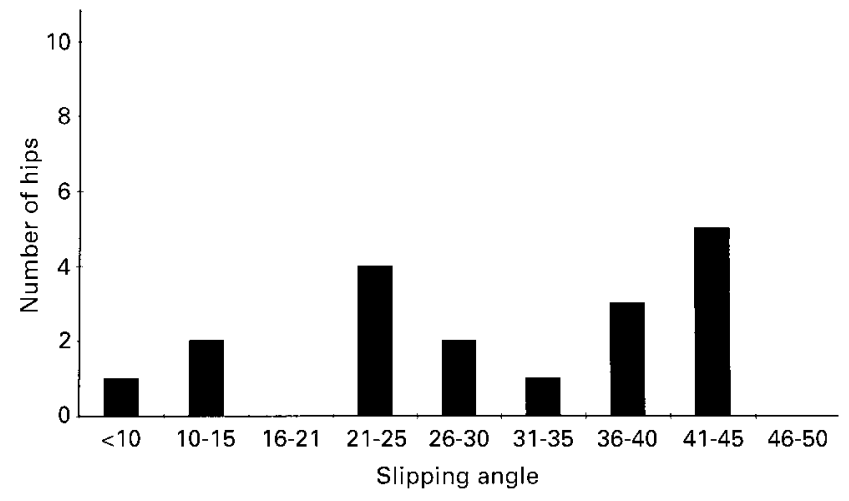

Fig. $4 b$

Radiological long-term results in 59 hips with SUFE nailed in situ, in relation to the SA at surgery. Figure 4a - Forty-one hips with no osteoarthritis (mean $24.6^{\circ} ; 12$ to 50 ). Figure $4 \mathrm{~b}$ - Eighteen hips with osteoarthritis (mean $30.2^{\circ} ; 9$ to 45 ). 
Table II. Clinical details in relation to the Harris hip score of 59 hips treated for SUFE 30 years after nailing in situ

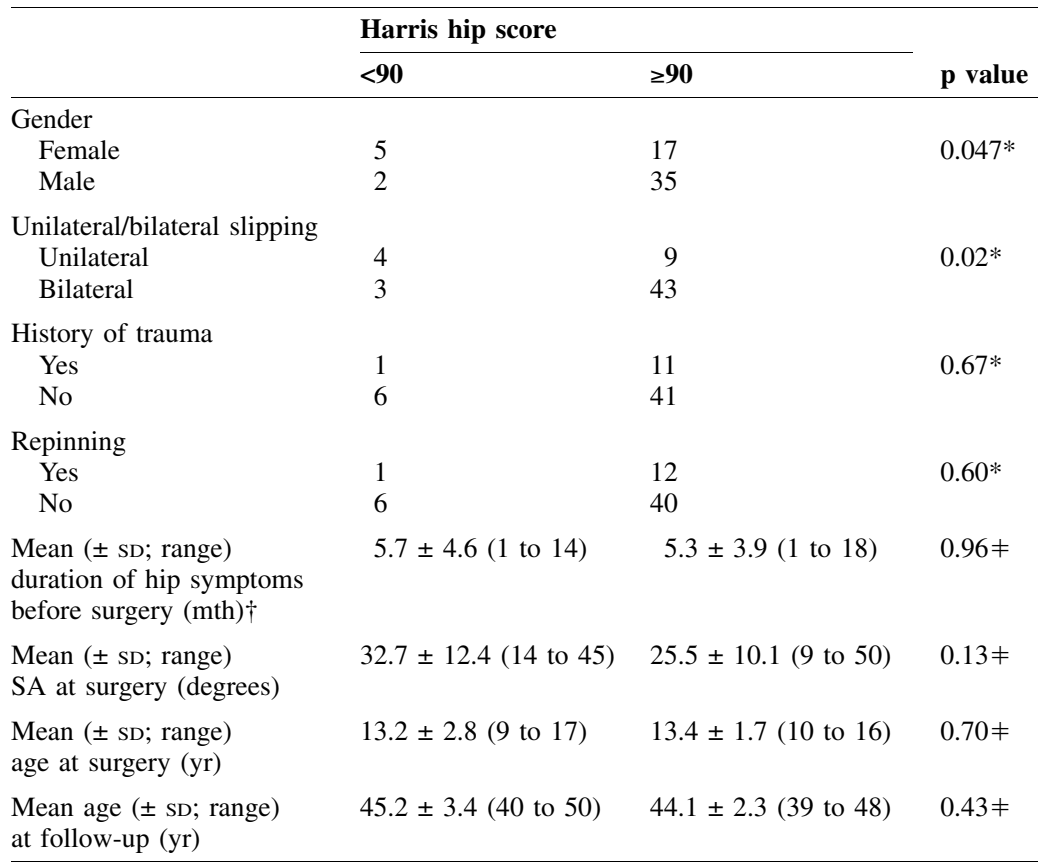

* chi-squared test

$\dagger 12$ hips with asymptomatic slipping excluded

₹ Mann-Whitney U test

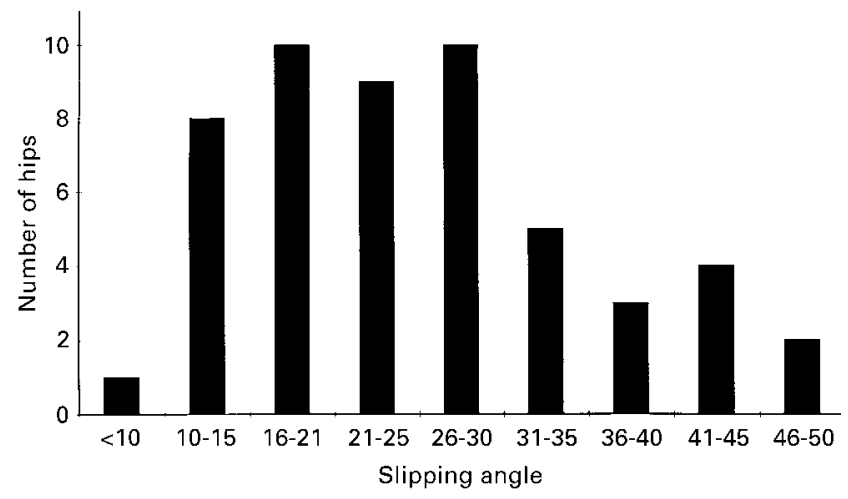

Fig. 5a

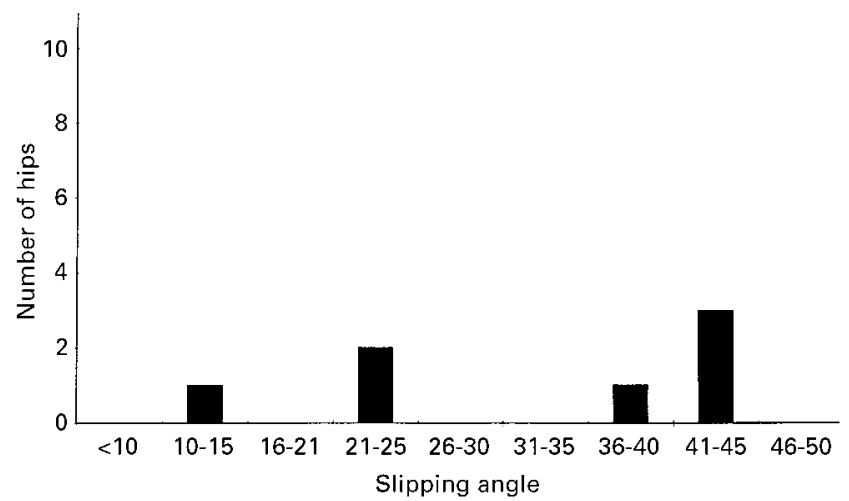

Fig. $5 b$

Clinical long-term results by HHS in 59 hips with SUFE nailed in situ, in relation to the SA at surgery. Figure 5a - Fifty-two hips with excellent results $\left(\mathrm{HHS} \geq 90\right.$ ) (mean $25.5^{\circ} ; 9$ to 50 ). Figure $5 \mathrm{~b}-$ Seven hips with fair or poor results (HHS <90) (mean $32.7^{\circ} ; 14$ to 45 ).

Table III. Radiological findings at follow-up in relation to clinical results assessed using the HHS

\begin{tabular}{lll}
\hline & \multicolumn{2}{l}{ Harris hip score } \\
\cline { 2 - 3 } Radiological findings & Mean \pm SD & Range \\
\hline Normal hips $(\mathrm{n}=41)$ & $95.9 \pm 7.7$ & 54.7 to 100 \\
Mild osteoarthritis $(\mathrm{n}=14)$ & $96.5 \pm 6.2$ & 75.1 to 100 \\
Severe osteoarthritis $(\mathrm{n}=4)$ & $74.3 \pm 28.3$ & 34.4 to 100 \\
\hline
\end{tabular}

patients needing renailing for this reason $(12.0 \pm 1.7$ years) compared with the remaining patients $(13.7 \pm 1.7$ years, $\mathrm{p}=0.008)$. Three other hips were renailed because the nail had started to extrude. One hip developed chondrolysis and one patient sustained a hip fracture 28 days after surgery.

\section{Observer agreement}

Slipping angle. The mean difference between the two measurements of the first observer was $0.18^{\circ}(99 \%$ limits of agreement -0.75 to +1.11 ) and for the second observer $0.28^{\circ}$ (99\% limits -0.38 to +0.94$)$. The mean value for the interobserver difference was $0.39^{\circ}$ ( $99 \%$ confidence limits -0.33 to +1.11$)$.

Joint space. The mean difference for joint space on review films for the first observer was $0.01 \mathrm{~mm}$ (99\% limits -0.08 to +0.07$)$ and for the second observer $0.03 \mathrm{~mm}(99 \%$ limits 
-0.05 to +0.11$)$. The mean interobserver difference was $0.09 \mathrm{~mm}$ (99\% limits 0.02 to 0.16 ).

\section{Discussion}

Several methods have been used to measure the displacement of the epiphysis in SUFE, including plain radiography, CT and ultrasonography. ${ }^{20,24-26}$ In most hips, slipping is by rotation of the epiphysis posteriorly, perpendicular to the plane of anteversion and therefore lateral views are necessary to allow reliable measurements. ${ }^{20,27}$

We measured the displacement of the epiphysis as the SA before surgery on plain radiographs obtained from each femur separately using the method introduced by one of the authors (LB, Fig. 1) in the 1950s. ${ }^{20}$ The displacement of the epiphysis is calculated by the measurement of an angle: this increases the accuracy of measurement. Use of a standard position and repeat lateral radiographs, which are sometimes required before the diagnosis can be established, allows the reliable comparison of serial views. Detection of the displacement is then possible at an early stage. Our high inter- and intraobserver agreement on measurement of the SA shows that it can be used to compare the severity of displacement in different series of patients with SUFE.

Any review of the long-term results requires an assessment of the presence of osteoarthritis, which implies an unsatisfactory result. Standard criteria and radiographic techniques are essential to assess these changes, but have not been used in some studies. This makes reliable comparison of radiographic results from different reports very difficult.

In an earlier study, we found that a combination of standing (weight-bearing) and modified frog lateral projections, which visualise the whole circumference of the articular space of the hip, is necessary to identify fully OA in hips previously treated for SUFE. ${ }^{22}$ This radiological method was also used in the present study. Furthermore, we consider that the actual measurement of the joint space is preferable to visual assessment of the radiographs; wider use of this would make it possible to compare radiographic results from different series.

In previous studies the long-term results after nailing in situ have been reported to be related to the severity of the slip at the time of surgery. ${ }^{28-30}$ Pinning in situ is mainly used for hips with mild slips while moderate or severe slips are treated by corrective osteotomy preferably at the trochanteric level. ${ }^{12,14,15}$ These previous studies do not show when the displacement is severe enough to justify osteotomy, because follow-up in most has been much too short.

The SA in our patients ranged from 7 to $50^{\circ}$, and we could therefore review only the results in hips with mild or moderate displacement. Within this range we found excellent long-term radiographic results: only four of 59 hips (7\%) had developed severe osteoarthritis. This percentage, however, is higher than that previously reported for the incidence of osteoarthritis of the hip in the normal population of a similar age in Sweden. ${ }^{31,32}$

We found no significant correlation between the degree of displacement at the time of surgery or any of the risk factors and the radiographic long-term results (Table I), but our series included only 18 hips $(30 \%)$ with an SA at the time of surgery of over $30^{\circ}$. It may therefore be possible that hips with an SA ranging from 31 to $50^{\circ}$ would have more correlation between the SA and long-term results. We conclude, however, that for chronic and acute-on-chronic slips with an SA ranging from 7 to $30^{\circ}$ nailing in situ is the procedure of choice. At present, we recommend that this also be used for hips with an SA ranging from 31 to $50^{\circ}$. For hips with slip over $50^{\circ}$, further studies, with at least 20 years' follow-up, are needed to reach a reliable choice between nailing in situ and corrective osteotomies.

The clinical long-term results were also good with only seven hips (12\%) recorded as fair or poor (Table II), and three of these had normal joint spaces in all five views. We found only a weak correlation between the displacement of the epiphysis and the long-term clinical results, but showed that a unilateral slip had a worse prognosis than a bilateral slip, as did females in relation to males (Table II). We found little correlation when assessing the radiographic results in a similar manner. It therefore seems possible that the clinical correlations which we found on statistical analysis could be explained by chance findings, sometimes seen when a large number of statistical tests are undertaken.

Our results showed that hips with mild radiographic OA had a mean HHS of 96.5 points, and those with severe OA a mean of 74.3 points (Table III). Thus, mild radiographic OA may not cause any major discomfort. Despite this it is essential to establish the diagnosis of mild OA in these patients since they are probably at risk of developing severe degeneration at a later date.

The complications of nailing in situ include nail penetration and inaccurate positioning, fractures of the femoral neck and at subtrochanteric level, and progression of the slip due to lost anchorage in the epiphysis. ${ }^{33-36}$ Removal of the nail, sometimes recommended to eliminate its stressriser effect, also has high complication rates. ${ }^{37}$ An experienced surgeon who is aware of the special anatomical problems of nailing these hips in situ can avoid most of these complications. The nail must enter the central part of the epiphysis, and it is therefore essential that the direction of the slip of the epiphysis is carefully studied on both the $\mathrm{AP}$ and lateral views at operation, using an image intensifier. Nail or pin penetration, with a reported incidence of $15 \%$ to $61 \%,^{34,36,38}$ can probably be avoided by awareness of the concept of 'the blind spot' on the AP and lateral views described by Walters and Simon ${ }^{38}$ and use of the 'approach-withdrawal phenomenon' during surgery as described by Moseley. ${ }^{39}$ Penetration is less common if one nail is used rather than several pins. ${ }^{40}$

Renailing because of loss of anchorage in the epiphysis can probably also be avoided in most cases. In our series 
renailing was performed in 13 hips (22\%), in ten because the femoral neck had continued to grow and in three because the nail had started to extrude. In the ten hips with continued growth the SA had been considerably smaller than average. Growth is likely to continue with an $\mathrm{SA}<20^{\circ}$ after nailing in situ; premature closure of the growth plate often occurs with $\mathrm{SA}>30^{\circ}$ and growth of the femoral neck stops soon after nailing. In hips with a small SA, it seems essential to use nails which offer good anchorage in the epiphysis itself.

We found no other adverse effects, such as avascular necrosis, from the insertion of the Nyström nail, but do not recommend its use as every fifth hip required reoperation for loss of anchorage. As argued above, the use of one nail is preferable to multiple pins, but it must be fixed in the epiphysis. Several such nails are available. The 'hook-pin' introduced by Hansson ${ }^{8}$ has the advantage of being easy to remove after the growth plate has fused. Nails with threaded ends, probably providing as safe an anchorage as the hook-pin, are sometimes extremely difficult to remove, ${ }^{37}$ and in the absence of local discomfort it is often advisable to leave such threaded implants in place.

\section{Conclusions}

1) Standard lateral radiographs of the proximal end of the femur by a modified Billing method ${ }^{20}$ allow reliable measurement of the displacement of the epiphysis. The SA has high inter- and intraobserver agreement.

2) Such measurements of hips with chronic and acute-onchronic slips give reliable information for selecting hips suitable for nailing in situ.

3) Technically correct nailing in situ for an $\mathrm{SA} \leq 30^{\circ}$, using a single thin nail, can provide excellent long-term radiological and clinical results.

4) Until there is more evidence, we recommend nailing in situ also for hips with an SA of 31 to $50^{\circ}$.

5) More long-term studies are needed to decide between nailing in situ and corrective osteotomy for larger slipping angles.

6) We recommend the use of a single thin nail designed to provide safe anchorage within the epiphysis.

We acknowledge financial support from Axel Tielman's Memorial Foundation. Figures 1 and 2 are published by kind permission of the Journal of Bone and Joint Surgery [Br]. We thank Britt-Louise Svensson and Halina Arvidsson for typing the manuscript.

No benefits in any form have been received or will be received from a commercial party related directly or indirectly to the subject of this article.

\section{References}

1. Oram V. Epiphysiolysis of the head of the femur: a follow-up examination with special reference to end results and social prognosis. Acta Orthop Scand 1953;23:100-20.

2. Stulberg SD, Cordell LD, Harris WH, Ramsey PL, MacEwen GD. Unrecognized childhood hip disease: a major cause of idiopathic osteoarthritis of the hip. In: The Hip. Procs 3rd meeting of The Hip Society. St Louis etc: CV Mosby Co, 1975:212-28.

3. Solomon L. Patterns of osteoarthritis of the hip. J Bone Joint Surg [Br] 1976;58-B:176-83.

4. Jerre T. Study in slipped upper femoral epiphysis with special reference to late functional and roentgenological results and to value of closed reduction. Acta Orthop Scand 1950, Suppl 6.
5. Ordeberg G, Hansson LI, Sandström S. Slipped capital femoral epiphysis in southern Sweden: long-term result with closed reduction and hip plaster spica. Clin Orthop 1987;220:148-54.

6. Wilson PD. The treatment of slipping of the upper femoral epiphysis with minimal displacement. J Bone Joint Surg 1938;20:379-99.

7. Severin E. Nailing in situ of slipped proximal epiphysis of the femur. Acta Orthop Scand 1955;24:145-54.

8. Hansson LI. Osteosynthesis with the hook-pin in slipped capital femoral epiphysis. Acta Orthop Scand 1982;53:87-96.

9. Heyman CH, Herndon CH. Epiphyseodesis for early slipping of the upper femoral epiphysis. J Bone Joint Surg [Am] 1954;36-A:539-55.

10. Grant IR. The treatment of slipped upper femoral epiphysis by fibular grafting. Clin Orthop 1976;114:270-5.

11. Melby A, Hoyt WA Jr, Weiner DS. Treatment of chronic slipped capital femoral epiphysis by bone graft epiphyseodesis. J Bone Joint Surg [Am] 1980;62-A:119-25.

12. Dunn DM. The treatment of adolescent slipping of the upper femoral epiphysis. J Bone Joint Surg [Br] 1964;46-B:621-9.

13. Wiberg G. Surgical treatment of slipped epiphysis with special reference to wedge osteotomy of the femoral neck. Clin Orthop 1966; 48:139-52.

14. Southwick WO. Osteotomy through the lesser trochanter for slipped capital femoral epiphysis. J Bone Joint Surg [Am] 1967;49-A: 807-35.

15. Abraham E, Garst J, Barmada R. Treatment of moderate to severe slipped capital femoral epiphysis with extracapsular base-of-neck osteotomy. J Pediatr Orthop 1993;13:294-302.

16. Mauer RC, Larsen IJ. Acute necrosis of cartilage in slipped capital femoral epiphysis. J Bone Joint Surg [Am] 1970;52-A:39-50.

17. Mankin HJ, Sledge CB. Chondrolysis of the hip. In: The hip. Procs of the 3rd meeting of The Hip Society. St Louis, etc: CV Mosby Co, 1975: 127-35.

18. Gage JR, Sunberg AB, Nolan DR, Sletten RG, Winter RB. Complications after cuneiform osteotomy for moderately or severely slipped capital femoral epiphysis. J Bone Joint Surg [Am] 1978; 60-A:157-65.

19. Billing L, Severin E. Slipping epiphysis of the hip: a roentgenological and clinical study based on a new roentgen technique. Acta Radiol Stockh 1959;Suppl 174:1-76.

20. Billing L. Roentgen examination of proximal femur end in children and adolescents: standardized technique also suitable for determination of collum-, anteversion-, and epiphyseal angles. Acta Radiol 1954;Suppl 110:1-80.

21. Billing L, Eklöf O. Slip of the capital femoral epiphysis: revival of a method of assessment. Pediatr Radiol 1984;14:413-8.

22. Hansson G, Jerre R, Sanders SM, Wallin J. Radiographic assessment of coxarthrosis following slipped capital femoral epiphysis. Acta Radiol 1993;34:117-23.

23. Harris WH. Traumatic arthritis of the hip after dislocation and acetabular fracture: treatment by mold arthroplasty. J Bone Joint Surg [Am] 1969;51-A:737-55.

24. Kulick RG, Denton JR. A retrospective study of 125 cases of slipped capital femoral epiphysis. Clin Orthop 1982;162:87-90.

25. Cohen MS, Gelberman RH, Griffin PP, et al. Slipped capital femoral epiphysis: assessment of epiphyseal displacement and angulation. J Pediatr Orthop 1986;6:259-64.

26. Terjesen T. Ultrasonography for diagnosis of slipped capital femoral epiphysis: comparison with radiography in 9 cases. Acta Orthop Scand 1992;63:653-7.

27. Griffith MJ. Slipping of the capital femoral epiphysis. Ann $R$ Coll Surg Engl 1976;58:34-42.

28. Klein A, Joplin RJ, Reidy JA, Hanelin J. Slipped capital femoral epiphysis: early diagnosis and treatment facilitated by 'normal' roentgenograms. J Bone Joint Surg [Am] 1952;34-A:233-9.

29. Hansson LI, Hägglund G, Ordeberg G, Sandström S. The calcar femorale as a landmark in hip physiolysis. Acta Orthop Scand 1988; 59:134-8.

30. Bianco AJ. Treatment of mild slipping of the capital femoral epiphysis. J Bone Joint Surg [Am] 1965;47-A:387-97.

31. Danielsson LG. Incidence of osteoarthritis of the hip (cox arthrosis). Clin Orthop 1966;45:67-72.

32. Danielsson L, Lindberg H, Nilson B. Prevalence of coxarthrosis. Clin Orthop 1984;191:110-5. 
33. Jerre T. Early complications after osteosynthesis with a three flanged nail in situ for slipped epiphysis. Acta Orthop Scand 1957;27: 126-34.

34. Lehman WB, Menche D, Grant A, Norman A, Pugh J. The problem of evaluating in situ pinning of slipped capital femoral epiphysis: an experimental model and a review of 63 consecutive cases. $J$ Pediatr Orthop 1984;4:297-303.

35. Crawford AH. Slipped capital femoral epiphysis. J Bone Joint Surg [Am] 1988;70-A:1422-7.

36. Segal LS, Robertson WW. Complications associated with the treatment of slipped capital femoral epiphysis. In: Epps $\mathrm{CH}$, Bowen JR, eds. Complications in pediatric orthopaedic surgery. Philadelphia: JB Lippincott, 1995:363-83.
37. Friberg S, Larsson S, Dahlström H. Complications associated with extraction of AO epiphysiodesis screw. Acta Orthop Scand 1984; 55:684.

38. Walters R, Simon SR. Joint destruction: a sequel of unrecognised pin penetration in patients with slipped capital femoral epiphyses. The Hip. Procs 8th Meeting of the Hip Society. St Louis, etc: CV Mosby Co, 1980:145-64.

39. Moseley CF. The 'approach - withdraw phenomenon' in the pinning of slipped capital femoral epiphysis. Orthop Trans 1985;9:497.

40. Stambough JL, Davidson RS, Ellis RD, Gregg JR. Slipped capital femoral epiphysis: an analysis of 80 patients as to pin placement and number. J Pediatr Orthop 1986;6:265-73. 